\title{
The Conceptive System of Keeping away Project Crisis
}

\author{
Peiyong Hou \\ Northwestern Polytechnical University \\ Xi'an 710072, Shaanxi, China \\ E-mail: hpynwpu@sohu.com \\ Ping Luo \\ Weinan Teachers College \\ Weinan 714000, Shaanxi, China \\ Yukan Hou \\ Northwestern Polytechnical University \\ Xi'an 710072, Shaanxi, China
}

This study is sponsored by the Policy Research Foundation of Northwestern Polytechnical University (ZC03020).

\begin{abstract}
In this paper, we regard the pattern of keeping away project crisis as research object. We carry through the system considers to project crisis in order to set up a condign emergency disposal pattern of taking precautions against crisis. We have analyzed the commonness and individuality between the public crisis and enterprise crisis totally. Societal operation and development had been under threat from these emergency crises seriously. It is urgent need for society development to constitute social crisis management system currently. The tradition theories and methods exists shortages that are in response to these emergency crisis. We could explore the inside regulation of the crisis activity, while is based on the scientific Views of development. Social crisis and public crisis could decompose to take advantage of the method of the project unit. This is a new availability crisis management mode to take from these emergency crises. We eluded the human psychology and behavior factors out of the analysis framework. We should understand what could do to manage in these emergency crises. The reliability theory will made as the platform of integrating risk management activities. We will improve the technique about the game in crisis management. The commonly rules are discussed in project crisis of our country. Moreover, a new crisis management system is proposed from conceptive views that precaution system can solve possible crisis in crisis process.
\end{abstract}

Keywords: Project management, Crisis, System analysis, Unconventionality decision-making

\section{Introduction}

The crisis is a frightening wording, which any society, nation and organize with individual cannot evade from its influence. The scientific and technological progress changes with each passing day. The economic globalization tide is turbulent at present. The social affiliation correlation is osculation increasingly. The multifarious contradiction and competes are anfractuosities. The affairs of sudden crisis are occurrence frequently. China is just in historical pass of per capita gross domestic product (GDP) 1000 dollars to 3000 dollars. This is the key period of a promising with risk. It makes public crisis into one high-incidence phase in the transition of economy and society. How do you dispose the emergency of public crisis? We must face the great subject. The keeping away project crisis with disposal is core of public crisis management. It is more important than the given crisis affairs of solution. The research about condign keeping away crisis with technology is important and practical for improving the ability of government to take precautions against crisis.

China is just in new development stage coexisting with opportunity and challenge. Many new changes have appeared in 
the crisis configuration all over the world today. Many projects have come forth rapidly with persistent reform and opening in China. There are challenges from dynamic changeful project environments and its inner order. It is a pressing and crucial task to study the crisis management issue of projects. Concretely, what can do in crisis management? What cannot do in crisis management? How the system is to elude hominine psychology and behavior factors out of the analysis framework? We will propose a new integrated crisis management system from systematic views. The technique of the game will improve in crisis management. The reliability theory will make as the platform of integrating risk management activities. We will realize a harmony between general crisis management theories and keeping away project crisis with disposal mode. We have kept to these thought paths of conceptual system, theory strategies, operation mechanism and empirical study, which indicates the issue-oriented characteristic of management study. We brought up several innovative standpoints. Such as, the source of projects crisis is the fault in projects system. We adopted the quantitative analysis method on researching problem of projects crisis. We applied the demonstration analysis way on researching reliability problem of preventing projects crisis. We have brought up scientific suggestion on keeping away arisen possible projects crisis with dissolving, while combined these researches the internal and international circumstance. The relevant countermeasure are proposed in crisis management system reformation, high crisis projects run surveillance, process management, projects stratagem, crisis precaution system startup and so on. Principal innovative conclusions are described as follows.

\section{Conception and characteristics}

It needs scientific method to understand crisis with crisis management. The crisis affairs with naturalness and production have took place more frequency and more multifarious form to spread to the seven seas. There is the immanent factor among them consequentially. The process of globalization trend development is that an integral course is full of opportunity, challenge and risk. In 2003, China gross domestic product (GDP) has already exceeded 1000 dollars. The gross domestic product (GDP) will exceed 3000 dollars in 2020. This is a sign that China modern developments have already entered a new stage. International experiences have made know that the nation will confronted with two kind outlooks from low income to higher income time, per capita gross domestic product (GDP) 1000 dollars to 3000 dollars. One outlook is come into prosperous development estate time in economy. Another outlook is relapse into high frequency and more multifarious crisis estate time. If these crises should not handle properly, a great deal of inconsistency would be likely to become acute. In addition, society economic development is likely to bog down. Maybe it even causes the social turbulence with fall back that would be alike some nation in Latin America. Therefore, the crisis is inevitable phenomenon of the society development in modern times. The crisis is also a risk expense of society economy high-speed disharmony development.

The crisis affairs have taken place more frequency and more multifarious form. The anarchy is appearing in crisis predicament. The crisis affairs with lifeblood, heart's-blood and moneybag check give prominence to society economy high-speed disharmony development in modern times, while society commonality ensured system is friability. These are refraction of government management disfigurement being short of position. The ability loss is exposure that government tunes up crisis selfhood. The crisis management system is so confusion currently that projects cause trouble but government paycheck. This is an extraordinary deviant phenomenon in crisis management.

This word about crisis has be make use of misuse or inaccuracy currently. The crisis has become the thesaurus of sudden affairs, emergencies or safety affairs and so on practically. As a matter of fact, their meaning of these words are not equal completely. The sudden affairs imply unexpected events to take place, but they are not influence the all progress indefinitely whether or how take order with them. The emergencies are mean corresponsive events quickly. The safety affairs are pointed harm events for person or body. They differ from the crisis affairs, but they may cause the crisis's occurrence.

The conception, characteristics and framework need to define in projects crisis management. This research is according to the management principle that simplexes valid management is best management under the crisis scenario. We have given the framework system of keeping away project crisis with disposal for the project management pattern of community organizes and vigorous pervasion of precaution thoughts. The inner connotation of keeping away project crisis with disposal is expatiated to suit unique attributes and development trends of Chinese commonality management. The project crisis is a state of paralytic and out-of-order affairs that has presented. From new thoughts of crisis management, we have given out the guidance meaning of projects paradigm. We indicated the specific realization ways of projects crisis partaken management supporting by project management. We have proposed the conception, characteristics and framework of projects crisis management of keeping away project crisis with disposal, for surpassing limits of traditional crisis management.

Barton take for the crisis is an indetermination event that can cause latent negative domino effect. (Barton L. Crisis in Organizations, 2001) This kind of affairs and its result may damage immensely for its personnel, product, serve, property with good reputation. He has designated as the crisis to have the appearance of these characteristics. One is to stand in amazement. The other is high menace for importance value. Third characteristic is to make the decision in short 
time expressly. Therefore, we can define the crisis to according to these. The crisis is a deadlock predicament of affairs to hang over badly all basic value and behavior guide line frame in system, while bring on normal movement system into disorder, discontinuer, destruction or paralysis state. It may threaten community safety or the principal part of the system to exist. It must make key decision in the time pressure with the indetermination circumstance. Our studying crisis management aimed at managing every kind of sudden affairs before the event and after the event, while those cannot presuppose when they take place in advance. However once these affairs occurrence would result in extreme dangerous for the system. The conception emphasized that crisis management is a time sequence. It includes the management before the crisis to explode. It includes the management after the crisis to explode too. The purpose of the crisis management is to decrease or to avoid harm by any possibility in the crisis course. The crisis management is also a process of summarizing and valuing law.

\section{Systematic function mechanism}

It is described that systematic function mechanism of projects crisis management may keep away project crisis with disposal. It is the basis of systematic crisis to be resolved strategies research from functional views. We published the five basic and objective crisis regulations on foundation to analysis inside inducement of outside environment in crisis. Focusing on special issues of projects crisis management of keeping away project crisis with disposal, we have given out three key influential factors of crisis that described their mutual functions. The three key influential factors are crisis-fountainhead, crisis-path and crisis-object in crisis.

The three key influential factors model of crisis are described as Figure 1 below. Any crisis can divide into three parts that are crisis-fountainhead, crisis-path and crisis-object. In the many earlier research, specialists developed the different type crisis diagram for the research of crisis affairs. We acknowledgement this is extraordinary difficult to bring up the mission of the concept frame for describing the crisis affairs. (Alexander Kouzmin, 2006, 5:35-41). Hereon, we use the following diagram to indicate the three key influential factors model of crisis. It is shown as Figure 1 below.

\section{Insert Figure 1 Here}

From the diagram, we can find a phenomenon. The crisis produced in part of project, but its bane and effect may be overall situation. We should adopt corresponding management tactic to aim at three parts of crisis. In usually circumstance, the preventing way is adapt to manage crisis-fountainhead. The segregating way is adapt to manage crisis-path. The urgent handling way is adapt to manage crisis-object.

We defined the modules of projects crisis management that can keep away project crisis with disposal system. The formed conceptual model is integrated each module. Basis of objective regulation of projects crisis activity, we discussed the possibility and necessity problem of the projects crisis precaution with advance design. The cost profit and loss worth space of keeping away crisis is given outs. Therefore, the mechanism issue of keeping away project crisis with disposal is revealed based on forming the dynamic model for this system. Accordingly, it has indicated that inner effective cooperation mechanism among each reliability module of keeping away project crisis with disposal in projects crisis management.

\section{Reliability regulation}

There are high risk and high crisis in future society. It will increase that one would be depend on other for existence degree. It will be deepen to depend upon liaison. The internationalization and socialization will be show by force. Development and crisis is chaperonage coexistence. The society development speed is to keep in touch with crisis degree closely. The variety of crisis is to interrelate the degree of society industrializes and the level of modernization nearly. That human being influences nature and society is gradually increased. The crisis probability moves up much more. The crisis strength deepens farther. The crisis frequency is speeding up. The crisis interlink is lengthening. The crisis spread to other quickly. The crisis involves the politics, economy, culture, society, military, environment, spirit and otherwise field. We could think that crisis is necessity phenomenon of the society high-speed disharmony development in modern times.

We can analyze the crisis development trend with oneself regulation according to the trend syllogism and growth curve method. We know that crisis is the thing out of line development as a result from quantitative changing to extent by the holy poker. This is also to say that crisis is must pass through time process necessarily. Therefore, no matter how abruptness the crises take place, there is a forecast interspaces in time process of the taking place crisis. At the same time, there is a daisy chain domino effect in crisis. The longer daisy chain of crisis system; the weaker link is the system.

Any crisis would dissolve to disappearance or clear up as proper motion, while obtain of oneself weak link or channel to set free oneself energy. If you could not make management for crisis efficaciously, it would be able to grown personal misfortune in all probability on the channel of release energy fully. If you could make management for crisis efficaciously, it would be able to be avail oneself of their energy in all probability. Thereby, the crisis provide with both sides characteristic. Meeting an emergency of crisis is only to play down their harm and expense or to shorten crisis 
duration, while fell back on expending the arm of flesh and material resources. Hereby, the crisis management is to need expend cost and benefit.

We have known distinctly that any crisis could divide into three parts of crisis-fountainhead, crisis-path and crisis-object. Any crisis-fountainhead is consisted in certain projects consequentially. As long as we could prevent the crisis-fountainhead, we would manage the crisis. Because the crisis-fountainhead can boil down to system reliability management in projects, the crisis management could boil down to system reliability management. Videlicet, to solve the matter of system reliability management implies to solve the matter of the crisis management. In this way, we could define that crisis of crisis-fountainhead inside of projects is the projects internal crisis. On the contrary, we could define that the crisis of crisis-fountainhead exterior of projects is the projects outer crisis. The project internal crisis is a topic for discussion of the system reliability in projects materially. The system reliability include mostly two-aspect problem. One is design limitation themselves. Another is the system management leak to reverberate oneself or outer crisis. The projects outer crisis include mostly natural or other project to be at the bottom of crisis. The operation firing into the wrong flock in key flow inside of projects is likely to cause catenation reaction for other projects exterior, while could down to be at the bottom of commonality crisis in society. This is conjunction of the projects internal crisis and the projects outer crisis. We may solve the management problem in the projects internal crisis and the projects outer crisis to make use of conjunction hereinbefore. On the contrary, we can break down common crisis in society to make use of conjunction hereinbefore.

Withal, the systematic reliability model of projects crisis management of keeping away project crisis with disposal is must form. We have studied the reliability strategies of project system based on the systematic function mechanism with the introduced reliability theory. We formed the dynamic model for this system with modularize, FTA (fault tree analysis) and process chain techniques. Focusing on unique targets of keeping away project crisis with disposal, we can solve key systematic failure of design disfigurement, management leak and emergency misplay. On fuzzy and stochastic characteristics of system process, the confirming method of keeping away project crisis with disposal has proposed by introducing reliability of keeping away project crisis model. We formed the two basal strategies of keeping away project crisis with disposal in projects crisis management for the actual scenario of the crisis process. The two basal strategies are these modes of series and parallel connection.

\section{Key hypothesis validated}

It is essential to validate key efficient hypothesis of keeping away project crisis with disposal empirically. This research investigated 30 example affairs of actual item crisis. We studied empirically for tow basic conclusions of this paper under a Chinese colliery project conditions. We proposed the empirical conceptual model based on above research of one basic and two derivative sub-hypothesis. Any crisis could divide into three parts that are also crisis-fountainhead, crisis-path and crisis-object. Any crisis-fountainhead is consisted in certain projects consequentially. Suppose the crisis-fountainhead could control, the crisis would be good for management. The matter of system reliability management to solve implies the matter of the crisis management to solve. We can break down common crisis in society by making use of conjunction of the projects internal crisis and the projects outer crisis hereinbefore. We have taken the overseas experiment observation methodology of physical science and engineering technology as the basic empirical study framework. The exploratory factor analysis and confirmatory factor analysis is implemented. The results of empirical study support two basic conclusions. The keeping away project crisis with disposal (redundancy degree) can promote project crisis management activities with the positive correlation. The costs of keeping away project crisis with disposal are important for crisis value losing in project with the negative correlation. It provides complete support for keeping away project crisis with disposal efficient hypothesis that precaution system can solve possibility crisis in crisis process. The results of keeping away project crisis with disposal would make projects crisis management itself to attain advancement in projects crisis management.

\section{References}

Alexander Kouzmin, Alan M.G. Jaman \& Enxin GAO (t). (2006). The policy is used as the crisis consults a new politics concept of crisis Management. Comparative Economic and Social Systems, 5: 35-41.

Barton L. (2001). Crisis in Organizations II. South-Western College Publishing/Thomson Learning.

Fink G, Haiss P R, Orlowski L \& Salvatore D. (1998). Central European banks and stock exchanges: Capacity-building and institutional development. European Management Journal, 16(4): 431-446.

Gai, P, Hayes S \& Shin H S. (2004). Crisis costs and debtor discipline: the efficacy of public policy in sovereign debt crises. Journal of International Economics, 62(2): 245-262.

Green D J. (2004). Investment behavior and the Economic Crisis in Indonesia. Journal of Asian Economics, 15(2): 287-303.

Rall M \& Dieckmann P. (2005). Safety culture and crisis resource management in airway management: General principles to enhance patient safety in critical airway situations. Best Practice \& Research Clinical Anesthesiology, 19(4): 539-557. 


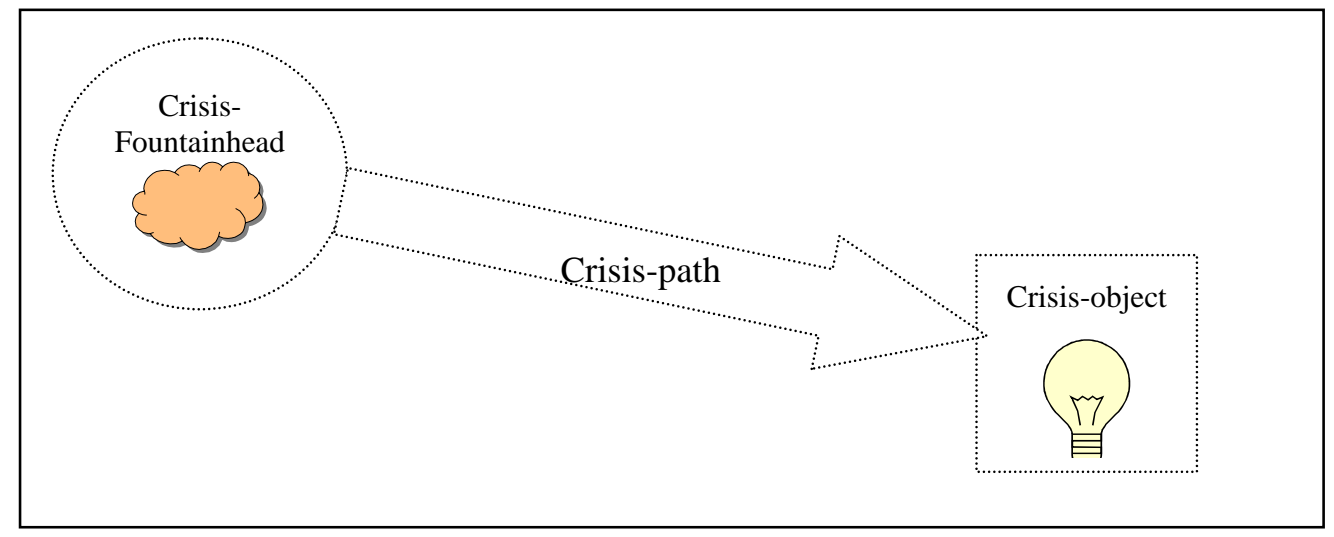

Figure 1. The three key influential factors model of crisis 